\title{
MASH1: a useful marker in differentiating pulmonary small cell carcinoma from Merkel cell carcinoma
}

\author{
Jonathan Ralston, Luis Chiriboga and Daisuke Nonaka \\ Department of Pathology, New York University School of Medicine, New York, NY, USA
}

\begin{abstract}
Merkel cell carcinoma is the cutaneous counterpart of small cell carcinoma, and the most important differential diagnosis is cutaneous metastasis of small cell carcinoma of the lung. There have been a handful of studies reporting on the utility of a variety of immunohistochemical markers that distinguish between the two entities. Achaete-scute complex-like 1 (MASH1, ASCL1) is important in the development of the brain and the diffuse neuroendocrine system including pulmonary neuroendocrine cells. A recent study, using a cDNA array, identified Mash1 as one of the best classifier genes to differentiate pulmonary small cell carcinoma from Merkel cell carcinoma. We immunohistochemically applied this finding to the diagnostic setting. A total of 30 cases of Merkel cell carcinoma and 59 cases of small cell carcinoma of the lung were immunostained with anti-MASH1 and TTF-1 antibodies. Of 59 small cell carcinomas, 49 (83\%) expressed MASH1 in nuclear staining whereas out of 59 small cell carcinomas, 43 (73\%) expressed TTF-1 in nuclear staining. MASH1 was completely negative in all 30 Merkel cell carcinomas whereas TTF-1 expression was seen in 1 of the 30 Merkel cell carcinomas (3\%). MASH1 is a useful adjunct marker for differentiating small cell carcinoma of the lung from Merkel cell carcinoma.

Modern Pathology (2008) 21, 1357-1362; doi:10.1038/modpathol.2008.118; published online 27 June 2008
\end{abstract}

Keywords: MASH1; Merkel cell carcinoma; small cell carcinoma of the lung; TTF-1

Merkel cell carcinoma is a rare aggressive neoplasm of the skin with a neuroendocrine phenotype, ${ }^{1,2}$ and it is regarded as the cutaneous counterpart of small cell carcinoma. ${ }^{2,3}$ It is morphologically very similar to small cell carcinomas of the lung and other organs, ${ }^{3}$ and its diagnosis requires confirmation by immunohistochemistry study, in conjunction with careful clinical and radiographic information, to rule out a metastatic small cell carcinoma, particularly from the lung. ${ }^{4}$ Achaete-scute complex-like 1 (ASCL1), also called mammalian or human achaetescute complex homolog-1 (MASH1, HASH1), is a basic helix-loop-helix transcription factor crucial for neuroendocrine cell differentiation. MASH1 has been reported to be expressed in some neuroendocrine neoplasms, including small cell carcinoma of the lung. ${ }^{5-7} \mathrm{~A}$ recent study using cDNA arrays on cell lines of small cell carcinoma of the lung and Merkel cell carcinoma demonstrated ASCL1 as one

Correspondence: Dr D Nonaka, MD, Department of Pathology, New York University School of Medicine, TCH-461, 560 First Avenue, New York, NY 10016, USA.

E-mail: daisuke.nonaka@med.nyu.edu

Received 14 March 2008; revised 01 May 2008; accepted 04 May 2008; published online 27 June 2008 of five genes specific for small cell carcinoma of the lung as opposed to Merkel cell carcinoma. ${ }^{8}$ In the current study, we applied this finding at the immunohistochemistry level to investigate the utility of an anti-MASH1 antibody in the diagnostic context.

\section{Materials and methods}

A total of 30 cases of Merkel cell carcinoma and 59 cases of pulmonary small cell carcinoma were studied. Hematoxylin and eosin-stained slides of all the cases were reviewed, and the histological diagnosis was based on recent classifications. ${ }^{2,9}$ Formalin-fixed, paraffin-embedded tissues of all the cases were used for tissue microarray construction. Tissue microarrays were assembled using a Manual Tissue Arrayer I (Beecher Instruments, Sun Prairie, WI, USA). A representative area of each case was identified on the conventional sections, and 1-3 cylinders per tissue were arrayed using a punch biopsy (needles with a diameter of $0.6 \mathrm{~mm}$ ). Afterward 4 out of the 30 Merkel cell carcinomas and 5 out of 59 pulmonary small cell carcinomas, in addition to the tissue microarray sections, were 
selected and examined using conventional whole sections.

Immunohistochemistry was performed on formalin-fixed, paraffin-embedded tissues using mouse anti-TTF-1 (clone 8G7G3/1; Neomarkers Freemont, CA, USA) and mouse anti-MASH1 (clone 24B7.2D11; BD Pharmingen, San Diego, CA, USA). Sections were deparaffinized in xylene (three changes), rehydrated through graded alcohols (three changes $100 \%$ ethanol, three changes $95 \%$ ethanol) and rinsed in distilled water. Heat-induced epitope retrieval was performed in a $1200 \mathrm{~W}$ microwave oven at $90 \%$ power in $10 \mathrm{mM}$ citrate buffer ( $\mathrm{pH} 6.0$ ). MASH1 was retrieved for $20 \mathrm{~min}$ and TTF-1 was retrieved for $15 \mathrm{~min}$, respectively. Sections were allowed to cool for $30 \mathrm{~min}$ and then rinsed in distilled water. Antibody incubations and detection were carried out at $37^{\circ} \mathrm{C}$ on a NEXes instrument (Ventana Medical Systems, Tucson, AZ, USA) using Ventana's reagent buffer and detection kits unless otherwise noted. Endogenous peroxidase activity was blocked with hydrogen peroxide. TTF-1 was diluted 1:50 and MASH1 was diluted 1:25, respectively. Antibodies were incubated overnight at room temperature. TTF-1 and MASH1 were detected with Ventana's biotinylated goat anti-mouse secondary. After secondary antibody application, streptavidinhorseradish-peroxidase conjugate was applied. The complex was visualized with 3,3'-diaminobenzidene and enhanced with copper sulfate. Slides were washed in distilled water, counterstained with hematoxylin, dehydrated and mounted with permanent media. Appropriate positive and negative controls were included with the study sections. The extent of nuclear staining was graded as follows: $1+, 1-25 \% ; 2+, 25-50 \% ; 3+, 50-75 \% ; 4+$, $\geq 75 \%$.

\section{Results}

The results of the immunohistochemistry study are listed in Table 1. Out of 59 small cell carcinomas, 49 (83\%; Figure 1a) expressed MASH1 in nuclear staining (Figure $1 \mathrm{~b})$, with a diffuse reaction $(3+$ and $4+$ ) being seen in 38 tumors $(61 \%)$ whereas out of 59 small cell carcinomas 43 (73\%) expressed TTF-1 in nuclear staining (Figure 1c), with a diffuse reaction being found in 34 tumors (58\%). The extent of MASH1 expression in small cell carcinomas was generally diffuse and similar to that of TTF-1 expression. Although many of the crushed cells of small cell carcinomas expressed TTF-1, they tended not to express MASH1. MASH1 was completely negative in all 30 Merkel cell carcinomas whereas TTF-1 expression was seen in 1 of the 30 Merkel cell carcinomas with $2+$ reaction (3\%; Figure $1 d-f)$. The latter case involved an 81-year-old man who presented with a $1.2 \mathrm{~cm}$ violaceous nodule on his left scalp, and the tumor was positive for cytokeratin (CK)20, chromogranin and synaptophysin, and negative for CK7. A thorough systemic examination failed to reveal any other tumorous lesions, thereby confirming its cutaneous origin. Overall, the sensitivity and specificity of MASH1 for distinguishing small cell carcinomas of the lung from Merkel cell carcinomas were 83 and $100 \%$, and those of TTF-1 were 73 and $97 \%$.

There was only one case of small cell carcinoma where MASH1 was negative and TTF-1 was positive with $2+$ reaction, whereas there were five small cell carcinomas where TTF-1 was completely negative and MASH1 was positive with $1+$ in one case, $3+$ in three cases, and $4+$ in one case.

\section{Discussion}

Merkel cell carcinoma, first described by Toker in 1972 as trabecular carcinoma of the skin, ${ }^{10}$ is a rare primary neuroendocrine carcinoma of the skin with an aggressive biological behavior, and it has been believed to originate from or differentiate toward Merkel cells in the outer sheath of the hair follicles and in sweat ducts, ${ }^{1,2,11}$ although rare cases arising in the lymph nodes, salivary gland and breast have been reported. ${ }^{12-15}$ The incidence of Merkel cell carcinoma has increased, presumably due to an increasing elderly population. ${ }^{4}$ Merkel cell carcinoma typically presents as a solitary, red to purple, firm, raised, painless nodule on the skin, ranging in size from $2-3 \mathrm{~mm}$ to several centimeters. ${ }^{1,2,4}$ It typically occurs in the sun-exposed areas of elderly patients, especially on the head and neck location, followed by the extremities. ${ }^{1,2}$ Merkel cell carcinoma shares many clinical, histopathological and

Table 1 Immunohistochemistry results for Merkel cell carcinoma and small cell carcinoma of the lung

\begin{tabular}{|c|c|c|c|c|c|c|c|c|c|c|c|c|}
\hline & \multicolumn{5}{|c|}{ MASH1 } & & \multicolumn{5}{|c|}{$T T F-1$} & \\
\hline & 0 & $1+$ & $2+$ & $3+$ & $4+$ & & 0 & $1+$ & $2+$ & $3+$ & $4+$ & \\
\hline Merkel cell carcinoma & 30 & 0 & 0 & 0 & 0 & $0 / 30(0 \%)$ & 29 & 0 & 1 & 0 & 0 & $1 / 30(3.3 \%)$ \\
\hline $\begin{array}{l}\text { Small cell carcinoma } \\
\text { of the lung }\end{array}$ & 10 & 3 & 8 & 8 & 30 & $49 / 59(83.1 \%)$ & 16 & 3 & 6 & 7 & 27 & $43 / 59(72.9 \%)$ \\
\hline
\end{tabular}

0 indicates no staining; $1+, 1-25 \%$ tumor cells reactive; $2+, 25-50 \%$ tumor cells reactive; $3+, 50-75 \%$ tumor cells reactive; $4+$, $\geq 75 \%$ tumor cells reactive. 

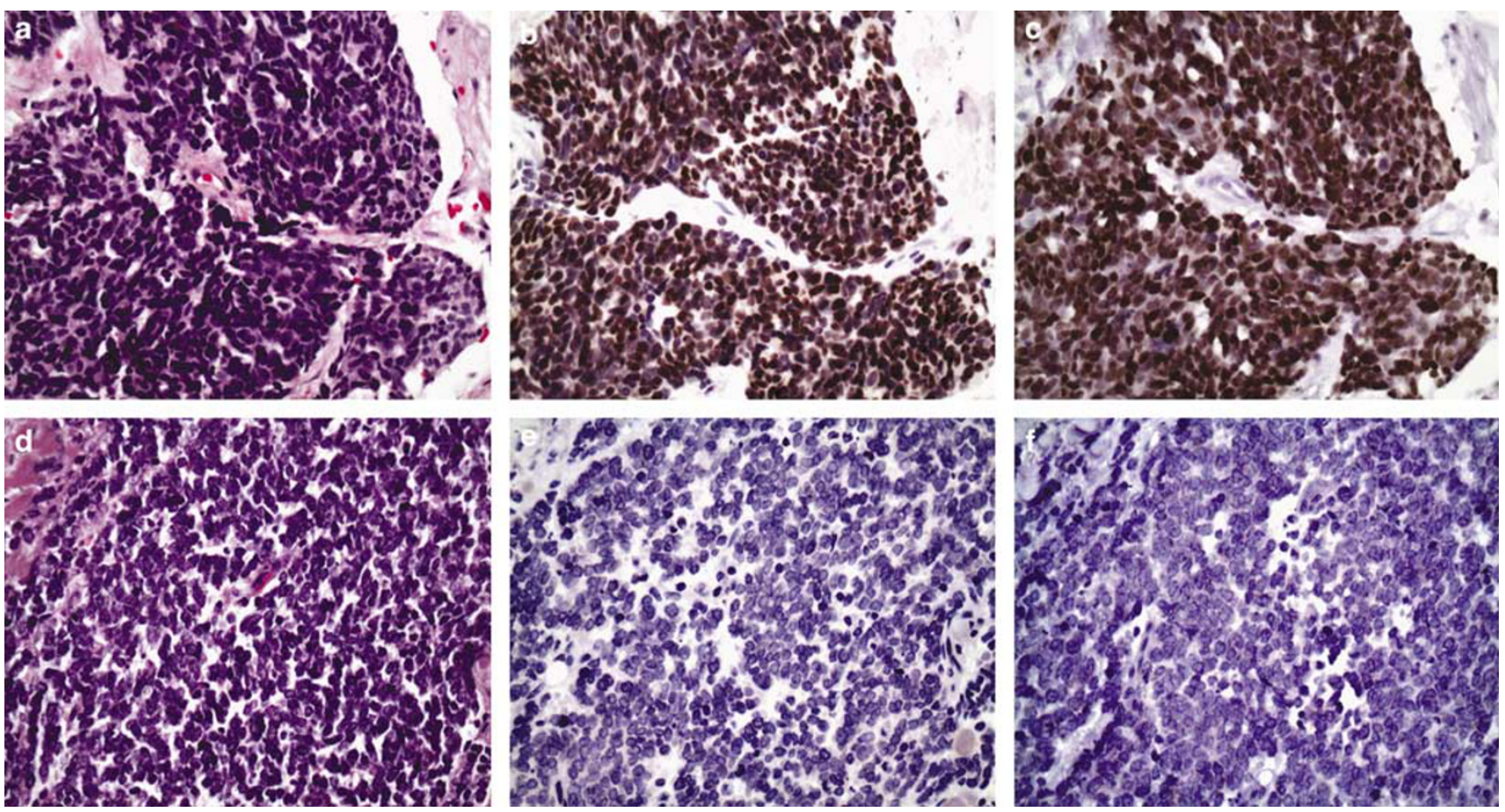

Figure 1 Small cell carcinoma of the lung: (a) hematoxylin and eosin (H\&E) stain, (b) MASH1 nuclear expression, (c) TTF-1 nuclear expression. Merkel cell carcinoma, (d) H\&E stain, (e) MASH1-negative reaction, (f) TTF-1-negative reaction.

genetic features with small cell carcinomas of other organs, including those of the lung, ${ }^{16}$ and in fact, it is regarded as the cutaneous counterpart of small cell carcinoma. ${ }^{2,3}$ It is currently recommended that patients be screened for small cell carcinoma of the lung to exclude the possibility of cutaneous metastasis of small cell carcinoma once a diagnosis of cutaneous Merkel cell carcinoma is made, illustrating the importance of determining reliable pathological markers to distinguish these lesions. ${ }^{4}$ Small cell carcinomas in general are now believed to originate from totipotential stem cells that can differentiate into various cell types that are native to the tissues, eg, TTF-1-positive stem cell for pulmonary small cell carcinoma. ${ }^{3}$ This hypothesis may explain occasional cases of small cell carcinoma with other components such as squamous cell carcinoma $^{17}$ and adenocarcinoma, ${ }^{18}$ the findings described in a variety of organs including skin and lung. ${ }^{17-20}$

Cutaneous metastasis of visceral carcinomas is usually an expression of the disseminated disease. $^{21,22}$ A skin metastasis, however, may be the presenting feature, and this phenomenon has been described most frequently in carcinomas of the lung, notably small cell carcinoma. ${ }^{23,24}$ The most common region of cutaneous metastasis of pulmonary small cell carcinoma is the skin of the trunk, followed by the skin of the head and neck, ${ }^{23,25}$ the latter being the most common site of Merkel cell carcinoma.

Subtle morphological differences between Merkel cell carcinoma and small cell carcinoma of the lung have been described. Merkel cell carcinoma typi- cally contains uniform round nuclei whereas small cell carcinoma shows irregular nuclei and can have a spindle shape in approximately $40 \%$ of tumors. ${ }^{18,26,27}$ Azzopardi phenomenon was first described in small cell carcinoma of the lung, and it is still a useful diagnostic finding. This phenomenon is rare in Merkel cell carcinoma. ${ }^{28,29}$ These general findings may not be applied in individual cases to determine the origin of the tumor due to overlapping features between the two entities. In fact, a subset of Merkel cell carcinoma can be indistinguishable from small cell carcinoma of the lung, and there have been a handful of immunohistochemistry studies to differentiate between the two. ${ }^{30-35}$

CK7/CK20 staining patterns can be useful in some cases, ie, $78 \%$ of Merkel cell carcinomas show a CK7 $(-) /$ CK20 $(+)$ pattern whereas $18-43 \%$ of small cell carcinomas of the lung show $\operatorname{CK} 7(+) /$ CK20(-). ${ }^{36,37}$ A significant proportion of both entities, particularly small cell carcinoma of the lung, however, express neither CK7 nor CK20, ie, 57-82\% of small cell carcinoma of the lung, and $12 \%$ of Merkel cell carcinoma, ${ }^{36,37}$ and exceptions can occur such as Merkel cell carcinomas that are $\operatorname{CK} 7(+) /$ CK20 $(-)^{31,32}$ or CK7 $(+) / C K 20(+)^{31}$ and such as small cell carcinomas of the lung that are CK7 $(-) /$ $\mathrm{CK} 20(+)$ or $\operatorname{CK} 7(+) / \mathrm{CK} 20(+) .^{33,37,38}$ TTF-1 is a sensitive and specific marker for small cell carcinoma of the lung, and it is expressed in approximately $80-90 \%$ of tumors. ${ }^{7,39-45}$ Currently a combination of CK20 and TTF-1 immunostains are used for the diagnosis of Merkel cell carcinoma. ${ }^{33-35}$ There are a few studies reporting TTF-1 expression in 
extrapulmonary small cell carcinoma by using monoclonal antibody of clone $8 \mathrm{G} 7 \mathrm{G} 3 / 1,{ }^{34,46-49}$ but no case of TTF-1-positive Merkel cell carcinoma has been reported to our knowledge. ${ }^{33-35,38}$ One of our cases of Merkel cell carcinoma unequivocally expressed TTF-1. This case, along with other extrapulmonary small cell carcinomas reported in the literature, illustrates that TTF-1 can be aberrantly expressed by small cell carcinomas of a variety of locations for yet an unknown reason.

TTF-1 is one of the most useful immunohistochemistry markers in diagnostic pathology, and it is a crucial transcription factor for the development of the lung and thyroid gland. In the lung, Ttf1 (Nkx2.1) regulates branching morphogenesis of the airways as well as terminal differentiation toward type II pneumocytes and Clara cells and their expression of surfactant proteins. ${ }^{50}$ TTF-1 is expressed in a great proportion of adenocarcinomas of the lung, ${ }^{51}$ most of which are believed to arise from the distal airways, and almost always negative in squamous carcinoma of the bronchus. It is a general observation that in adenocarcinoma of the lung, TTF-1 expression roughly correlates with the degree of differentiation of the tumor, ie, the better differentiated the tumor is, the greater TTF-1 expression. ${ }^{45}$ The fact that TTF-1 is expressed in small cell carcinoma more frequently than adenocarcinoma supports the notion that small cell carcinoma is a tumor of totipotential stem cells that are programmed to differentiate toward the lung phenotype, and in this sense, small cell carcinoma is an underdifferentiated carcinoma rather than an undifferentiated carcinoma, the latter often being used to refer to this entity. ${ }^{52}$

Mash1 is important in the development of the brain and the diffuse neuroendocrine system including adrenal medullary chromaffin cells, ganglion cells, thyroid parafollicular $\mathrm{C}$ cells and pulmonary neuroendocrine cells. ${ }^{53}$ During neurogenesis MASH1 expression is confined to mitotically active precursors where it is involved in the early stages of lineage commitment, and in more mature neurons the expression is extinguished. ${ }^{53}$ Mash1 and mammalian atonal homolog-1 (Math1) upregulate NeuroD in neural precursor cells to direct terminal differentiation whereas Hes1, one of the hairy and Enhancer of split homologs, represses neuronal differentiation by suppression of proneural factors such as Mash $1 .{ }^{5}$ This developmental process also appears to take place in pulmonary carcinomas where small cell carcinomas express Mash1 but not Hes1 whereas adenocarcinoma and squamous cell carcinoma express Hes1. ${ }^{5}$

Previous studies reported that MASH1 was immunohistochemically expressed in $71.8^{6}$ and $87 \%{ }^{7}$ of small cell carcinoma of the lung. The frequency of MASH1 expression in small cell carcinoma in our series is $83.1 \%$ and is comparable to those of the previous studies. A previous study demonstrated MATH1 expression in Merkel cells of the skin as well as Merkel cell carcinoma cell line but not MASH1 expression, and concluded that Math1, instead of Mash1, might be required for maintenance of the neuroendocrine phenotype in Merkel cell carcinoma. ${ }^{54}$ A recent study, using a cDNA array on cell lines of Merkel cell carcinoma and pulmonary small cell carcinoma, identified 17 classifier genes capable of discriminating between the two entities. ${ }^{8}$ Among the 17 genes, 12 genes were Merkel cell carcinoma specific, and 5 genes were pulmonary small cell carcinoma specific, the latter including Mash1 (ASCL1). MASH1 was not expressed in any of 30 Merkel cell carcinomas in the current study, but was more frequently expressed in small cell carcinoma of the lung than TTF-1. Our results support the findings of the previous molecular studies at the immunohistochemical level.

In summary, MASH1 is a useful adjunct marker for the diagnosis of small cell carcinoma of the lung, particularly when the differential diagnosis includes Merkel cell carcinoma. Given the variable CK7/CK20 pattern reported in some Merkel cell carcinomas and small cell carcinomas of the lung, and potential TTF-1 expression in nonpulmonary neuroendocrine carcinomas including Merkel cell carcinoma, MASH1 is a useful marker, with slightly higher sensitivity than TTF-1, and can be used in a panel of immunostains in conjunction with TTF-1, CK7 and CK20.

\section{References}

1 Sibley RK, Dehner LP, Rosai J. Primary neuroendocrine (Merkel cell?) carcinoma of the skin. I. A clinicopathologic and ultrastructural study of 43 cases. Am J Surg Pathol 1985;9:95-108.

2 Kohler S, Kerl H. Merkel cell carcinoma, neural tumours. In: Leboit PE, Burg G, Weedon G, Sarasin A (eds). Skin Tumours. IARC Press: Lyon, 2006, pp 272-273.

3 Shahab N, Mirza IA, Doll D. Extrapulmonary small cell carcinoma. Semin Oncol 2007;34:1-2.

4 Bichakjian CK, Lowe L, Lao CD, et al. Merkel cell carcinoma: critical review with guidelines for multidisciplinary management. Cancer 2007;110:1-12.

5 Ito T, Udaka N, Okudela $\mathrm{K}$, et al. Mechanisms of neuroendocrine differentiation in pulmonary neuroendocrine cells and small cell carcinoma. Endocr Pathol 2003;14:133-139.

6 Jiang SX, Kameya T, Asamura H, et al. hASH1 expression is closely correlated with endocrine phenotype and differentiation extent in pulmonary neuroendocrine tumors. Mod Pathol 2004;17:222-229.

7 Hiroshima K, Iyoda A, Shida T, et al. Distinction of pulmonary large cell neuroendocrine carcinoma from small cell lung carcinoma: a morphological, immunohistochemical, and molecular analysis. Mod Pathol 2006;19:1358-1368.

8 Van Gele M, Boyle GM, Cook AL, et al. Geneexpression profiling reveals distinct expression patterns for classic versus variant Merkel cell phenotypes and new classifier genes to distinguish Merkel cell 
from small-cell lung carcinoma. Oncogene 2004; 23:2732-2742.

9 Travis WD, Brambilla E, Muller-Hermelink HK, et al. Tumours of the lung. In: Travis WD, Brambilla E, Muller-Hermelink HK, Harris CC (eds). Pathology and Genetics, Tumours of the Lung, Pleura, Thymurs, and Heart. IARC Press: Lyon, 2004, pp 9-124.

10 Toker C. Trabecular carcinoma of the skin. Arch Dermatol 1972;105:107-110.

11 Santa Cruz DJ, Bauer EA. Merkel cells in the outer follicular sheath. Ultrastruct Pathol 1982;3:59-63.

12 Eusebi V, Capella C, Cossu A, et al. Neuroendocrine carcinoma within lymph nodes in the absence of a primary tumor, with special reference to Merkel cell carcinoma. Am J Surg Pathol 1992;16:658-666.

13 Fotia G, Barni R, Bellan C, et al. Lymph nodal Merkel cell carcinoma: primary or metastatic disease? A clinical case. Tumori 2002;88:424-426.

14 Kraemer BB, Mackay B, Batsakis JG. Small cell carcinomas of the parotid gland. A clinicopathologic study of three cases. Cancer 1983;52:2115-2121.

15 Papotti M, Macri L, Finzi G, et al. Neuroendocrine differentiation in carcinomas of the breast: a study of 51 cases. Semin Diagn Pathol 1989;6:174-188.

16 Frazier SR, Kaplan PA, Loy TS. The pathology of extrapulmonary small cell carcinoma. Semin Oncol 2007;34:30-38.

17 Gomez LG, DiMaio S, Silva EG, et al. Association between neuroendocrine (Merkel cell) carcinoma and squamous carcinoma of the skin. Am J Surg Pathol 1983;7:171-177.

18 Nicholson SA, Beasley MB, Brambilla E, et al. Small cell lung carcinoma (SCLC): a clinicopathologic study of 100 cases with surgical specimens. Am J Surg Pathol 2002;26:1184-1197.

19 Sidhu GS, Feiner H, Flotte TJ, et al. Merkel cell neoplasms. Histology, electron microscopy, biology, and histogenesis. Am J Dermatopathol 1980;2: 101-119.

20 Tang CK, Toker C, Nedwich A, et al. Unusual cutaneous carcinoma with features of small cell (oat cell-like) and squamous cell carcinomas. A variant of malignant Merkel cell neoplasm. Am J Dermatopathol 1982;4:537-548.

21 Abrams HL, Spiro R, Goldstein N. Metastases in carcinoma; analysis of 1000 autopsied cases. Cancer 1950;3:74-85.

22 Mehregan AH. Metastatic carcinoma to the skin. Dermatologica 1961;123:311-325.

23 Brownstein MH, Helwig EB. Metastatic tumors of the skin. Cancer 1972;29:1298-1307.

24 Rosen T. Cutaneous metastases. Med Clin North Am 1980;64:885-900.

25 Tharakaram S. Metastases to the skin. Int J Dermatol 1988;27:240-242.

26 Schmidt U, Metz KA, Richter HJ, et al. Merkel cell carcinoma: histomorphology and immunohistochemistry of 76 cases. Am J Dermatopathol 1997;19:501.

27 Share SM, Cham EM, Mohanty A, et al. Can histomorphologic findings separate Merkel cell carcinoma from small cell carcinoma? [Abstract]. Mod Pathol 2008; 21:102A.

28 Vazmitel M, Michal M, Kazakov DV. Merkel cell carcinoma and Azzopardi phenomenon. Am J Dermatopathol 2007;29:314-315.

29 Schmidt U, Muller U, Metz KA, et al. Cytokeratin and neurofilament protein staining in Merkel cell carcinoma of the small cell type and small cell carcinoma of the lung. Am J Dermatopathol 1998; 20:346-351.

30 Shah IA, Netto D, Schlageter MO, et al. Neurofilament immunoreactivity in Merkel-cell tumors: a differentiating feature from small-cell carcinoma. Mod Pathol 1993;6:3-9.

31 Jensen K, Kohler S, Rouse RV. Cytokeratin staining in Merkel cell carcinoma: an immunohistochemical study of cytokeratins 5/6, 7, 17, and 20. Appl Immunohistochem Mol Morphol 2000;8:310-315.

32 Calder KB, Coplowitz S, Schlauder S, et al. A case series and immunophenotypic analysis of CK20-/ CK7+ primary neuroendocrine carcinoma of the skin. J Cutan Pathol 2007;34:918-923.

33 Hanly AJ, Elgart GW, Jorda M, et al. Analysis of thyroid transcription factor- 1 and cytokeratin 20 separates Merkel cell carcinoma from small cell carcinoma of lung. J Cutan Pathol 2000;27:118-120.

34 Cheuk W, Kwan MY, Suster S, et al. Immunostaining for thyroid transcription factor 1 and cytokeratin 20 aids the distinction of small cell carcinoma from Merkel cell carcinoma, but not pulmonary from extrapulmonary small cell carcinomas. Arch Pathol Lab Med 2001;125:228-231.

35 Leech SN, Kolar AJ, Barrett PD, et al. Merkel cell carcinoma can be distinguished from metastatic small cell carcinoma using antibodies to cytokeratin 20 and thyroid transcription factor 1. J Clin Pathol 2001;54:727-729.

36 Chu P, Wu E, Weiss LM. Cytokeratin 7 and cytokeratin 20 expression in epithelial neoplasms: a survey of 435 cases. Mod Pathol 2000;13:962-972.

37 Wang NP, Zee S, Bacchi CE, et al. Coordinate expression of cytokeratins 7 and 20 defines unique subsets of carcinomas. Appl Immunohistochem 1995;3:99-107.

38 Byrd-Gloster AL, Khoor A, Glass LF, et al. Differential expression of thyroid transcription factor 1 in small cell lung carcinoma and Merkel cell tumor. Hum Pathol 2000;31:58-62.

39 Zhang H, Liu J, Cagle PT, et al. Distinction of pulmonary small cell carcinoma from poorly differentiated squamous cell carcinoma: an immunohistochemical approach. Mod Pathol 2005;18:111-118.

$40 \mathrm{Wu} \mathrm{M}$, Wang $\mathrm{B}$, Gil J, et al. p63 and TTF-1 immunostaining. A useful marker panel for distinguishing small cell carcinoma of lung from poorly differentiated squamous cell carcinoma of lung. Am J Clin Pathol 2003;119:696-702.

41 Sturm N, Rossi G, Lantuejoul S, et al. Expression of thyroid transcription factor-1 in the spectrum of neuroendocrine cell lung proliferations with special interest in carcinoids. Hum Pathol 2002;33:175-182.

42 Nakamura N, Miyagi E, Murata S, et al. Expression of thyroid transcription factor-1 in normal and neoplastic lung tissues. Mod Pathol 2002;15:1058-1067.

43 Di Loreto C, Di Lauro V, Puglisi F, et al. Immunocytochemical expression of tissue specific transcription factor-1 in lung carcinoma. J Clin Pathol 1997;50: 30-32.

44 Folpe AL, Gown AM, Lamps LW, et al. Thyroid transcription factor-1: immunohistochemical evaluation in pulmonary neuroendocrine tumors. Mod Pathol 1999;12:5-8.

45 Jerome MV, Mazieres J, Groussard O, et al. Expression of TTF-1 and cytokeratins in primary and secondary 
epithelial lung tumours: correlation with histological type and grade. Histopathology 2004;45:125-134.

46 Jones TD, Kernek KM, Yang XJ, et al. Thyroid transcription factor 1 expression in small cell carcinoma of the urinary bladder: an immunohistochemical profile of 44 cases. Hum Pathol 2005;36:718-723.

47 Agoff SN, Lamps LW, Philip AT, et al. Thyroid transcription factor-1 is expressed in extrapulmonary small cell carcinomas but not in other extrapulmonary neuroendocrine tumors. Mod Pathol 2000;13: 238-242.

48 Ordonez NG. Value of thyroid transcription factor-1 immunostaining in distinguishing small cell lung carcinomas from other small cell carcinomas. Am J Surg Pathol 2000;24:1217-1223.

49 Kaufmann O, Dietel M. Expression of thyroid transcription factor-1 in pulmonary and extrapulmonary small cell carcinomas and other neuroendocrine carcinomas of various primary sites. Histopathology 2000;36:415-420.

50 Kimura J, Deutsch GH. Key mechanisms of early lung development. Pediatr Dev Pathol 2007;10:335-347.

51 Ordonez NG. Thyroid transcription factor-1 is a marker of lung and thyroid carcinomas. Adv Anat Pathol 2000;7:123-127.

52 Gephardt GN, Grady KJ, Ahmad M, et al. Peripheral small cell undifferentiated carcinoma of the lung. Clinicopathologic features of 17 cases. Cancer 1988;61: 1002-1008.

53 Wang XY, Dakir el H, Naizhen X, et al. Achaete-scute homolog-1 linked to remodeling and preneoplasia of pulmonary epithelium. Lab Invest 2007;87:527-539.

54 Leonard JH, Cook AL, Van Gele M, et al. Proneural and proneuroendocrine transcription factor expression in cutaneous mechanoreceptor (Merkel) cells and Merkel cell carcinoma. Int J Cancer 2002;101:103-110. 